\title{
TITLE:
}

\section{Fatigue Life Properties and Availability of Proof Testing in Ceramics-Coated Glass}

\section{$\operatorname{AUTHOR}(\mathrm{S}):$}

Hoshide, Toshihiko; Shimizu, Shohei; Tanaka, Motoki

\section{CITATION:}

Hoshide, Toshihiko ...[et al]. Fatigue Life Properties and Availability of Proof Testing in Ceramics-Coated Glass. Journal of Materials Engineering and Performance 2013, 23(3): 753-758

\section{ISSUE DATE:}

2013-12-27

URL:

http://hdl.handle.net/2433/196869

\section{RIGHT:}

The final publication is available at Springer via http://dx.doi.org/10.1007/s11665-0130844-0; This is not the published version. Please cite only the published version.; この論文 は出版社版でありません。引用の際には出版社版をご確認ご利用ください。 
Fatigue Life Properties and Availability of Proof testing in Ceramics-Coated Glass

Toshihiko Hoshide ${ }^{1)}$, Shohei Shimizu ${ }^{2)}$ and Motoki Tanaka ${ }^{2)}$

1) Department of Energy Conversion Science, Kyoto University, Kyoto 606-8501, Japan

2) Graduate School of Energy Science, Kyoto University, Kyoto 606-8501, Japan

\begin{abstract}
The long-term durability of high-performance ceramics-coated glass should be appropriately evaluated prior to their practical applications. Fatigue properties of such materials should be clarified to ensure the long-term durability. In this work, a borosilicate glass was coated with alumina or silicon carbide thin films by sputtering method. Fatigue tests of coated glass were conducted under three-point bending. It was clarified that the fatigue life was elongated by coating ceramic thin films on glass and the fatigue life distribution in glass coated with thicker films shifted toward longer life region. Proof testing was carried out for coated glass specimens to remove specimens having lower fatigue lives. It was suggested that proof testing for fatigue of ceramics coated glass was effective as a screening procedure which can remove weaker specimens by static pre-loading before fatigue tests. In correlating average fatigue lives, fatigue resistance strength was introduced as the average bending strength divided by the applied maximum stress. It was revealed that the average fatigue lives of every coated glass, including average lives after proof testing, were well correlated by a power function of the fatigue resistance strength and its modified parameter, irrespective of film material and thickness and also applied stress level.
\end{abstract}

Keywords: Fatigue; coated glass; ceramic coating film; life distribution; proof testing; bending strength; hardness 


\section{Introduction}

Glass materials coated with ceramic materials by sputtering are applied to various engineering apparatuses and components. Recent works reported that glass coated with ceramic thin film is functionally used as magnetic/electronic device materials (Ref 1-3) as well as optical ones (Ref 1, 4-7). In functional and/or mechanical applications of ceramics coated glass, it is anticipated that they may suffer serious damages due to cyclic mechanical or thermal stresses. Consequently, to improve the long-term durability in their practical applications, the structural design of systems using ceramics coated glass requires a fundamental understanding of their fatigue characteristics.

In the present work, fatigue behavior of a borosilicate glass coated with alumina $\left(\mathrm{Al}_{2} \mathrm{O}_{3}\right)$ or silicon carbide $(\mathrm{SiC})$ were experimentally investigated to clarify the fatigue life properties. A radio frequency $(\mathrm{RF})$ magnetron sputtering method was adopted in producing thin ceramic films on glass. Coated glass materials were prepared by changing the film thickness for each ceramic film material. Hardness of coating films and strength of coated glass were measured as static characteristics of coated glass. Since axial loading tests, such as tensile tests, of brittle glass or ceramic materials are very difficult to be performed in evaluating their strength characteristics adequately (e.g. Ref 8), static strength and fatigue tests were conducted under bending mode, instead of axial loading mode. Fatigue life distributions of glass coated with ceramic films having different thicknesses were investigated. It is convenient that fatigue characteristics obtained by long-time tests can be evaluated by using static strength properties given in short-time tests. Therefore, the average fatigue life was correlated with hardness, static strength and fatigue resistance strength, which was proposed in a previous work (Ref 9), and resultant correlations were discussed.

Information on the minimum life of coated materials should be mandatory in their fatigue design. It was revealed, however, that fatigue life distribution has a large dispersion. Consequently, some techniques to guarantee the minimum life are required. In this work, a procedure using proof testing is focused on as one of screening methods which can remove weaker specimens by static pre-loading before fatigue tests. Proof testing was carried out for coated glass materials before starting their fatigue tests and the effect of proof testing on life distribution was examined based on results in fatigue tests of specimens surviving after proof testing.

\section{Experimental procedures}

\subsection{Material processing}

A commercial borosilicate glass, TEMPAX $^{\circledR}$, was used as a substrate material. TEMPAX ${ }^{\circledR}$ consists of $81 \% \mathrm{SiO}_{2}, 13 \% \mathrm{~B}_{2} \mathrm{O}_{3}, 4 \% \mathrm{Na}_{2} \mathrm{O} / \mathrm{K}_{2} \mathrm{O}$ and $2 \% \mathrm{Al}_{2} \mathrm{O}_{3}$. Alumina $\left(\mathrm{Al}_{2} \mathrm{O}_{3}\right)$ of $99.99 \%$ purity and silicon carbide ( $\mathrm{SiC}$ ) of $99.8 \%$ purity were adopted as target materials. The geometry of glass substrate was a disk type with a diameter of $100 \mathrm{~mm}$ and a thickness of $2 \mathrm{~mm}$. In the present work, each ceramic film was coated on glass substrate by sputtering procedure as mentioned below, and the thickness $t_{\mathrm{f}}$ of coated film was controlled to be $1 \mu \mathrm{m}, 3$ $\mu \mathrm{m}$ or $5 \mu \mathrm{m}$. Sputtered ceramic films as well as the substrate glass have amorphous microstructures, and then observed microstructures appear to be featureless.

An RF magnetron sputtering apparatus of upper deposit type was used in the coating process. The distance between substrate and each target material was set to be $40 \mathrm{~mm}$ in this apparatus. Substrate and target materials were being water-cooled during the processing. Before starting a steady sputtering, pre-sputtering was carried out for $300 \mathrm{~s}$ so that a contaminated layer of target material could be removed. The initial degree of vacuum in a processing chamber was kept less than $1.3 \times 10^{-4} \mathrm{~Pa}$. The flow-rate and pressure of argon gas, 
which was used to activate the sputtering process in the chamber, were controlled to be 167 $\mathrm{mm}^{3} / \mathrm{s}$ and $1.3 \mathrm{~Pa}$, respectively. The initial temperature of substrate could be controlled, though the substrate temperature could not be controlled during sputtering of ceramic target materials. The RF output power was set to be $600 \mathrm{~W}$.

Specimens of plate type with dimensions of $10 \mathrm{~mm}$ in width and $50 \mathrm{~mm}$ in length were cut out from coated glass and the glass substrates themselves for static strength tests and fatigue tests under bending mode.

\subsection{Measurements of film hardness and static bending strength}

The surface hardness of coated materials was measured by using dynamic microhardness tester. To avoid the influence of the substrate hardness on the film hardness, an ultra-low loaded hardness tester is appropriate in measuring the film hardness (Ref 10-12). The hardness $H$ is defined as $H=\alpha\left(F / D^{2}\right)$, in which $\alpha=3.86$, and $F$ and $D$ are respectively indentation force in $\mathrm{mN}$ and depth of indenter in $\mu \mathrm{m}$ (Ref 13). The indenter used in the tester is a Berkovitch type. The indentation force $F$ was set to be $98 \mathrm{mN}$ in this work.

Three-point bending tests with span length of $20 \mathrm{~mm}$ were conducted to evaluate the static bending strength of glass substrate and ceramics coated glass. The bending tests were carried out under force-controlled condition. Since materials tested in this study are too brittle, nominal stresses generated in bending mode before ultimate fracture are proportional to applied forces. The force rate in loading was controlled so that the rate of nominal stress at the position subjected to the maximum tensile stress in a specimen should be $100 \mathrm{MPa} / \mathrm{s}$. The stress rate of $100 \mathrm{MPa} / \mathrm{s}$ had been used in our previous works, which was adopted to prevent the slow crack growth during bending tests.

In setting a coated specimen on supporting equipment, the coated surface of the specimen was located in the tensile side. Fifteen specimens were prepared for each sputtering conditions. All tests were carried out in an ambient atmosphere.

\subsection{Procedures of fatigue tests and proof testing}

Fatigue tests of glass substrate and ceramics coated glass were conducted under a sinusoidal loading at a frequency of $20 \mathrm{~Hz}$. The loading mode in fatigue tests and the setting of specimens were as same as those mentioned in the static bending strength tests. All tests were conducted in an ambient atmosphere. The maximum stress $\sigma_{\max }$ generated in each specimen was controlled to be $70 \mathrm{MPa}$ or $80 \mathrm{MPa}$ during the fatigue tests. Theses maximum stress levels were selected to be lower than the lowest strength in static bending tests. A stress ratio $R$, which is defined as the ratio of minimum stress to maximum stress, was set to be 0.1 . Each fatigue test under $\sigma_{\max }=70 \mathrm{MPa}$ or $80 \mathrm{MPa}$ was stopped when one day (24 hours) passed without failure. A number of cycles at stopping fatigue test after 24 hours is $1.728 \times 10^{6}$ cycles.

Proof testing is noticed as one of screening procedures, which can remove weaker components among a group of the components. In this work, proof testing was done for one specimen before its fatigue test. The loading in proof testing was a type of triangular wave with constant stress-rates of $100 \mathrm{MPa} / \mathrm{s}$ in loading up to a proof stress and $-100 \mathrm{MPa} / \mathrm{s}$ in unloading. The proof stress $\sigma_{\mathrm{p}}$ was set to be $100 \mathrm{MPa}$ in this work. Subsequent fatigue tests of specimens surviving after proof testing were conducted under the same conditions as the aforementioned fatigue test.

\section{Experimental results and discussions}

\subsection{Hardness of coating films and strength of coated materials}

Table 1 summarizes static strength properties, i.e. average hardness $H_{\text {ave }}$ of coating film 
and average bending strength $\sigma_{\mathrm{f} \text {,ave }}$ of glass coated with ceramic film. Here, the average values of $H_{\text {ave }}$ and $\sigma_{\mathrm{f} \text {,ave }}$ imply the arithmetical means of fifteen strength values measured in each material. For reference, the average hardness and strength of glass substrate are also presented in Table 1. The static strength properties of every coated glass are larger than respective properties of glass substrate. It is found that coating of ceramic films results in the improvement of static strength of glass. In each coated material, the hardness and strength become higher as the film thickness is increased. This trend is more clearly seen in $\mathrm{SiC}$ coated glass. Table 1 reveals that $\mathrm{SiC}$ coated glass is harder than $\mathrm{Al}_{2} \mathrm{O}_{3}$ coated one, though $\mathrm{SiC}$ coated glass is a little weaker than $\mathrm{Al}_{2} \mathrm{O}_{3}$ coated one.

The hardness and strength of ceramic materials such as $\mathrm{Al}_{2} \mathrm{O}_{3}$ and $\mathrm{SiC}$ are generally higher than those of glass materials mainly consisting of $\mathrm{SiO}_{2}$. Therefore, it is speculated that the aforementioned improvement in hardness and strength may be attributed to coating ceramic films harder and stronger than a glass material, though there is no clear evidence to verify such a speculation.

\subsection{Fatigue properties of coated glass}

\section{(1) Fatigue life properties in stress- life relations}

Figures 1 and 2 show variations of fatigue life $N_{\mathrm{f}}$ of glass coated with $\mathrm{Al}_{2} \mathrm{O}_{3}$ or $\mathrm{SiC}$ film under $\sigma_{\max }=70 \mathrm{MPa}$ and $80 \mathrm{MPa}$, respectively. Numbers attached to arrows in the figures correspond with the numbers of specimens surviving at the truncated number of cycles, i.e., $1.728 \times 10^{6}$ cycles. In these figures, fatigue lives of glass substrates under $\sigma_{\max }=70 \mathrm{MPa}$ and $80 \mathrm{MPa}$ are also depicted for reference. As seen in Figs. 1 and 2, the distribution of lives of specimens of every material, which were broken during fatigue tests, has a large dispersion, similarly to such a scatter as observed in static strength of monolithic ceramics. However, it seems that the minimum life shifts toward longer life region as decreasing an applied stress, and the number of surviving specimens is obviously larger under lower applied stress. It is seen that, comparing with fatigue lives of glass substrate, lives of glass coated with each ceramic film shift toward longer life region. In glass coated with $\mathrm{SiC}$ films, lower lives are observed than those of $\mathrm{Al}_{2} \mathrm{O}_{3}$ coated glass. As a whole trend for the same film material, fatigue life distributions of glass coated with thicker films shift toward longer life region.

In the following, the average fatigue life, $N_{\mathrm{f}, \text { ave }}$, is introduced as one of representative parameters, which enable us to investigate fatigue life property quantitatively, though the meaning of average value is problematic. Figure 3 presents the variation of the average fatigue life with respect to the film thickness. Here, the average value also implies the arithmetical mean. Dotted straight lines for $\sigma_{\max }=70 \mathrm{MPa}$ and $80 \mathrm{MPa}$ are drawn in Fig. 3 to show rough trends of the variations. The relations of dotted lines are approximated by fitting data of glass substrate and glass coated with ceramic films to exponential functions. Concerning the average fatigue life, too, it is seen that the average fatigue lives of ceramic film coated glass are longer than that of glass substrate, and the average fatigue life in glass coated with thicker films seems to become longer. It is noted that the variation of $N_{\mathrm{f} \text {,ave }}$ in changing the film thickness is very large under $\sigma_{\max }=80 \mathrm{MPa}$ compared with that under $\sigma_{\max }$ $=70 \mathrm{MPa}$, though the difference in average lives under $\sigma_{\max }=70 \mathrm{MPa}$ and $80 \mathrm{MPa}$ is small in glass coated with film of $5 \mu \mathrm{m}$ thickness.

As mentioned in Section 3.1, ceramic materials such as $\mathrm{Al}_{2} \mathrm{O}_{3}$ and $\mathrm{SiC}$ are generally harder and stronger than glass materials. It is also speculated that the aforementioned improvement in fatigue properties may be attributed to coating harder and stronger ceramic films. Unfortunately, in this case, too, there is no clear evidence to verify such a speculation.

\section{(2) Correlations of average fatigue life with some static parameters}


In this section, the average fatigue life $N_{\mathrm{f} \text {,ave }}$ is focused on as one of representative parameters in fatigue life distribution, and is correlated with some static parameters, which can be obtained rapidly and easily in experiments.

At first, the average fatigue life is correlated with the average hardness $H_{\text {ave }}$ in Fig. 4. Dotted straight lines in Fig. 4 indicate power functions of $H_{\text {ave }}$ fitted to average fatigue lives of glass substrate and glass coated with ceramic films for respective two levels of $\sigma_{\max }$. Secondarily, the average fatigue life is correlated with the average bending strength $\sigma_{\mathrm{f} \text {,ave }}$ in Fig. 5. Dotted straight lines in Fig. 5 express the relations of $N_{\text {f,ave }}$ of glass substrate and glass coated with ceramic films, which are approximated as power functions of $\sigma_{\mathrm{f} \text {,ave }}$ for respective two levels of $\sigma_{\max }$. By comparing results depicted in Figs. 4 and 5, it is seen that the average fatigue lives of glass coated with ceramic films can be more appropriately presented by the correlation with the average bending strength. However, the two approximated relations for $\sigma_{\max }=70 \mathrm{MPa}$ and $80 \mathrm{MPa}$ are separated each other as a matter of course.

In a previous work (Ref 9), a new strength parameter was proposed to correlate the average fatigue lives of glass coated with single- or two-layered ceramic films. The parameter was designated as fatigue resistance strength, $S_{\text {res }}$, and it was defined as the average bending strength $\sigma_{\text {f,ave }}$ divided by the applied maximum stress $\sigma_{\text {max }}$; i.e.

$S_{\text {res }} \equiv\left(\sigma_{\mathrm{f}, \mathrm{ave}} / \sigma_{\max }\right)$

Figure 6 presents the relation between average fatigue lives and fatigue resistance strength. As seen in the figure, almost all of average fatigue lives are correlated by a power function of the fatigue resistance strength, irrespective of film material and maximum stress applied in fatigue tests. The solid straight line in Fig. 6 represents a power function expressed as;

$N_{\text {f,ave }}=5.14 \times 10^{3}\left(S_{\text {res }}\right)^{15.7}$

Equation (2) is obtained by the best fitting for the results of glass substrate and glass coated with ceramic films. The relation given by Eq. (2) almost coincides with the relation in the previous work (Ref 9). In Fig. 6, two dotted straight lines are also drawn to show a scatter band of a factor of three. By using the fatigue resistance strength, the average fatigue lives of glass coated with ceramic films is almost estimated within the scatter range of a factor of three, independently of material and thickness of coated film as well as applied stress level.

\section{Effect of proof testing on life distribution}

In this part, an availability of proof testing is examined in guaranteeing the minimum life in fatigue of glass coated with ceramic thin films.

Life distributions in fatigue tests conducted after proof testing are depicted in Figs. 7 and 8. Solid marks in these figures present the minimum lives in ordinary fatigue tests of respective film materials as shown in Figs. 1 and 2. In every material, it is seen that the minimum lives in fatigue tests conducted after proof testing is longer than their corresponding minimum lives in the ordinary fatigue tests. Consequently, it may be concluded that the proof testing conducted under the condition set in this work is successfully applicable to removal of specimens having lower fatigue lives. This coincides with the result in bulk monolithic ceramics that the proof testing is effective for screening weaker specimens under fatigue (Ref 14).

The average fatigue lives in the ordinary fatigue tests and in the fatigue tests conducted after proof testing are compared in Fig. 9. As seen in Fig. 9, longer average fatigue lives are obtained by conducting proof testing before fatigue tests. Concerning the average fatigue life, 
too, the availability of proof testing is confirmed in removing specimens with lower fatigue lives.

In correlating the average fatigue lives in fatigue tests conducted after proof testing, the proposed fatigue resistance strength should be modified by replacing the average strength $\sigma_{\mathrm{f} \text {,ave }}$, of the whole bending strength with another adequate strength parameter in Eq. (1). It is reasonable to consider that strength of specimens surviving after proof testing is higher than the proof stress, i.e. $100 \mathrm{MPa}$, if there is no damage during proof testing. Therefore, the

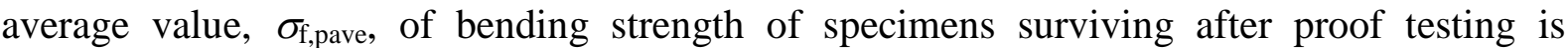
employed as the strength parameter to be replaced in Eq. (1). Here, the average value also implies the arithmetical mean. The modified fatigue resistance strength $S_{\text {res }}^{\prime}$ is defined as follows.

$S_{\text {res }}^{\prime} \equiv\left(\sigma_{\mathrm{f}, \mathrm{pave}} / \sigma_{\max }\right)$

Figure 10 shows the relation between the average fatigue lives $N_{\mathrm{f}, \text { ave }}$ in fatigue tests conducted after proof testing and the modified fatigue resistance strength $S_{\text {res. }}^{\prime}$ The solid straight line in Fig. 10 presents the relation of Eq. (2), and the dotted lines show a band of a factor of three. It is revealed that almost all data are included within the scatter band for the result observed in the ordinary fatigue tests, though the results under $\sigma_{\max }=70 \mathrm{MPa}$ seem to shift toward slightly lower life region.

\section{Conclusions}

Fatigue properties of coated materials with high performance should be investigated to guarantee their long-term durability and integrity. This work aimed at clarifying fatigue life property as one of the durability characteristics of such materials as well as constructing a procedure to determine their minimum lives for fatigue design. In the present work, a borosilicate glass was coated with alumina or silicon carbide thin films by a radio frequency magnetron sputtering method, and the thickness $t_{\mathrm{f}}$ of coated film was prepared to be $1 \mu \mathrm{m}, 3$ $\mu \mathrm{m}$ or $5 \mu \mathrm{m}$. Fatigue tests of coated glass were conducted under three-point bending mode and at stress ratio of 0.1 .

Although a large dispersion was observed in experimental life distributions, it was clarified that the fatigue strength was improved by coating ceramic thin films on glass. It was also found that the fatigue life distribution and the average life in glass coated with thicker film shifted toward longer life region. Hardness as surface characteristics of coated films, and bending strength as bulk property of coated glass were correlated with the average fatigue life. However, no good correlation was found between them.

To guarantee the minimum fatigue life, proof testing was applied for all specimens before conducting their fatigue tests. Specimens with lower lives in ordinary fatigue tests were successfully removed by proof testing. The proof testing was found to be an effective procedure in screening out fatigue lives of ceramics coated glass.

In correlating fatigue life with a static strength parameter, the fatigue resistance strength was introduced as the average bending strength divided by the applied maximum stress. It was clarified that the average fatigue lives of every coated glass, including average lives after proof testing, were fairly expressed by a power function of the fatigue resistance strength and its modified parameter, independently of material and thickness of coated film as well as applied stress level.

\section{References}


1. K.H. Kim, K.C. Park and D.Y. Ma, Structural, Electrical and Optical Properties of Aluminum Doped Zinc Oxide Films Prepared by Radio Frequency Magnetron Sputtering, J Appl Phys, 1997, 81, p 7764-7772

2. Y. Fukuma, H. Asada, N. Nishimura and T. Koyanagi, Ferromagnetic Properties of IV-VI Diluted Magnetic Semiconductor $\mathrm{Ge}_{1-\mathrm{x}} \mathrm{Mn}_{\mathrm{x}} \mathrm{Te}$ Films Prepared by Radio Frequency Sputtering, J Appl Phys, 2003, 93, p 4034-4039

3. Y. Peng, C. Park and D.E. Laughlin, $\mathrm{Fe}_{3} \mathrm{O}_{4}$ Thin Films Sputter Deposited from Iron Oxide Targets, J Appl Phys, 2003, 93, p 7957-7959

4. D.A. Chang, P. Lin and T.Y. Tseng, Optical Properties of $\mathrm{ZrTiO}_{4}$ Films Grown by Radio-Frequency Magnetron Sputtering, J Appl Phys, 1995, 77, p 4445-445 1

5. G.T. Kiehne, G.K.L. Wong and J.B. Ketterson, Optical Second-Harmonic Generation in Sputter-Deposited AlN Films, J Appl Phys, 1998, 84, p 5922-5927

6. H. Mizoguchi, N. Kitamura, K. Fukumi, T. Mihara, J. Nishii, M. Nakamura, N. Kikuchi, H. Hosono and H. Kawazoe, Optical Properties of $\mathrm{SrMoO}_{3}$ Thin Film, J Appl Phys, 2000, 87, p 4617-4619

7. S. Venkataraj, O. Kapperiz, H. Weis, R. Drese, R. Jayavel and M. Wuttig, Structural and Optical Properties of Thin Zirconium Oxide Films Prepared by Reactive Direct Current Magnetron Sputtering, J Appl Phys, 2002, 92, p 3599-3607

8. T. Hoshide, Strength Characteristics of Structural Ceramics, Mater Sci Res Int, 1996, 2, p 220-228

9. T. Hoshide, M. Tanaka and H. Tsujiai, Fatigue Properties of Borosilicate Glass Coated with Two-Layered Ceramic Thin Films, J Mater Eng Perform, 2013, 22, p 1079-1084.

10. T. Hoshide, A. Nebu and K. Hayashi, Bending Strength of Borosilicate Glass Coated with Alumina and Silicon Carbide by RF Magnetron Sputtering, JSME Int J, Ser A, 1998, 41, p 332-337

11. T. Hoshide, K. Hayashi, T. Saito, K. Katsuki and T. Inoue, Mechanical Properties of Borosilicate Glass Coated with Alumina by Sputtering Process, Mater Sci Res Int, 1996, 2 , p 33-38

12. P.J. Burnett and D.S. Rickerby, Assessment of Coating Hardness, Surface Eng, 1987, 3, p 69-76

13. Japanese Industrial Standard, Method for ultra-low loaded hardness test, JIS Z 2255, 2003

14. Hoshide T., Proof Testing and Subsequent Fatigue Properties of Ceramics. Current Jap Mater Res 1995, 14, p 207-232 
Table 1 Static strength properties of glass coated with single-layered ceramic film

\begin{tabular}{|c|c|c|c|c|c|}
\hline \multirow{2}{*}{ Mechanical property } & \multicolumn{3}{|c|}{ Glass coated with single-layered ceramics } & \multirow{2}{*}{$\begin{array}{c}\text { Glass } \\
\text { substrate }\end{array}$} \\
\cline { 2 - 5 } & $\begin{array}{c}\text { Film } \\
\text { material }\end{array}$ & $1 \mu \mathrm{m}$ & $3 \mu \mathrm{m}$ & $5 \mu \mathrm{m}$ & \\
\cline { 2 - 5 } $\begin{array}{c}\text { Average hardness } \\
H_{\text {ave }}\end{array}$ & $\mathrm{Al}_{2} \mathrm{O}_{3}$ & 314 & 338 & 362 & \multirow{2}{*}{282} \\
\cline { 2 - 5 } & $\mathrm{SiC}_{2}$ & 345 & 369 & 390 & \\
\hline $\begin{array}{c}\text { Average bending } \\
\text { strength } \sigma_{\mathrm{f}, \text { ave }}\end{array}$ & $\mathrm{Al}_{2} \mathrm{O}_{3}$ & $97.2 \mathrm{MPa}$ & $99.4 \mathrm{MPa}$ & $99.5 \mathrm{MPa}$ & \multirow{2}{*}{$88.5 \mathrm{MPa}$} \\
\cline { 2 - 5 } & $\mathrm{SiC}$ & $91.9 \mathrm{MPa}$ & $96.6 \mathrm{MPa}$ & $98.6 \mathrm{MPa}$ & \\
\hline
\end{tabular}

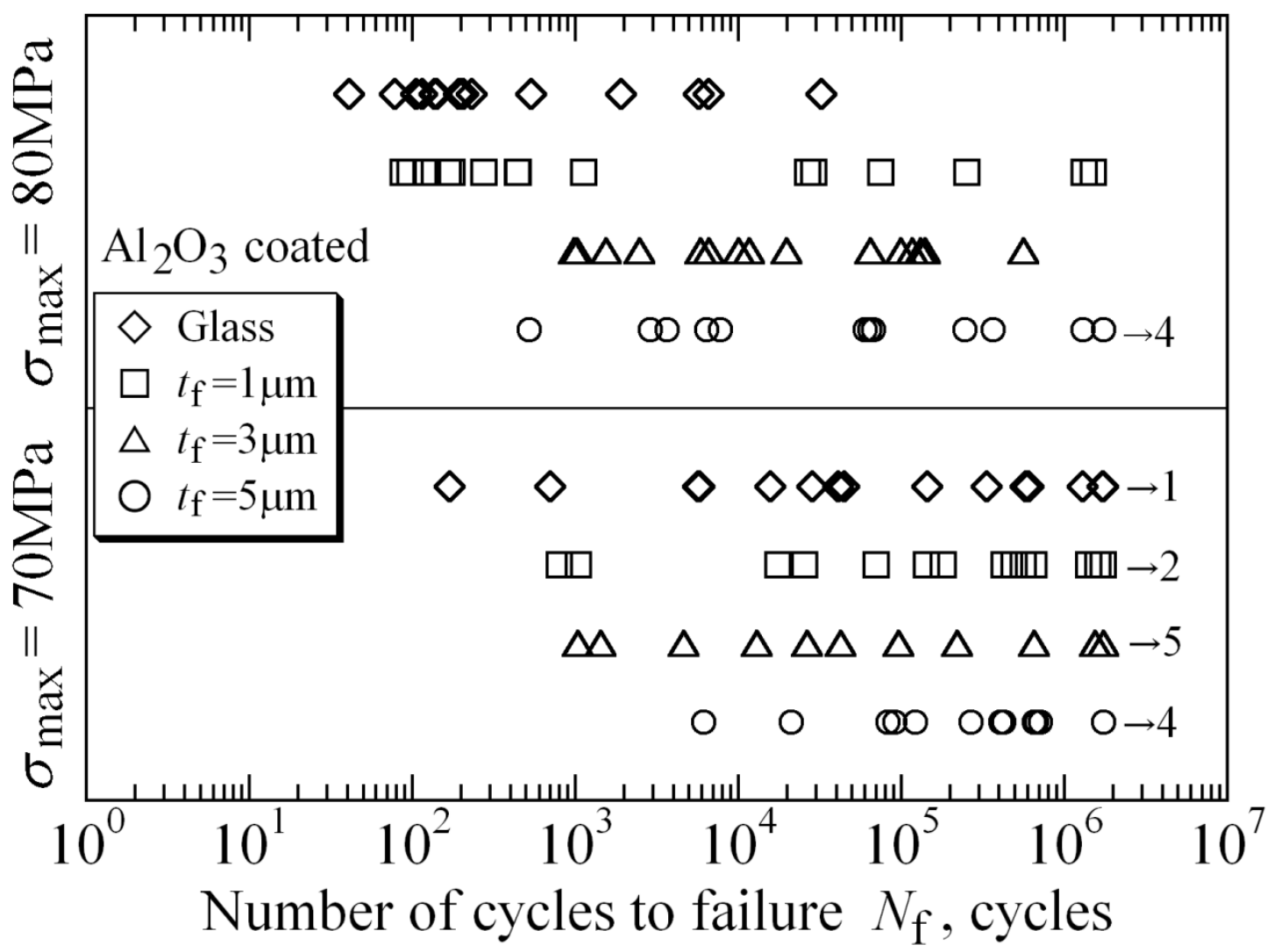

Fig. 1 Fatigue life of $\mathrm{Al}_{2} \mathrm{O}_{3}$ coated glass under $\sigma_{\max }=70 \mathrm{MPa}$ and $80 \mathrm{MPa}$ 


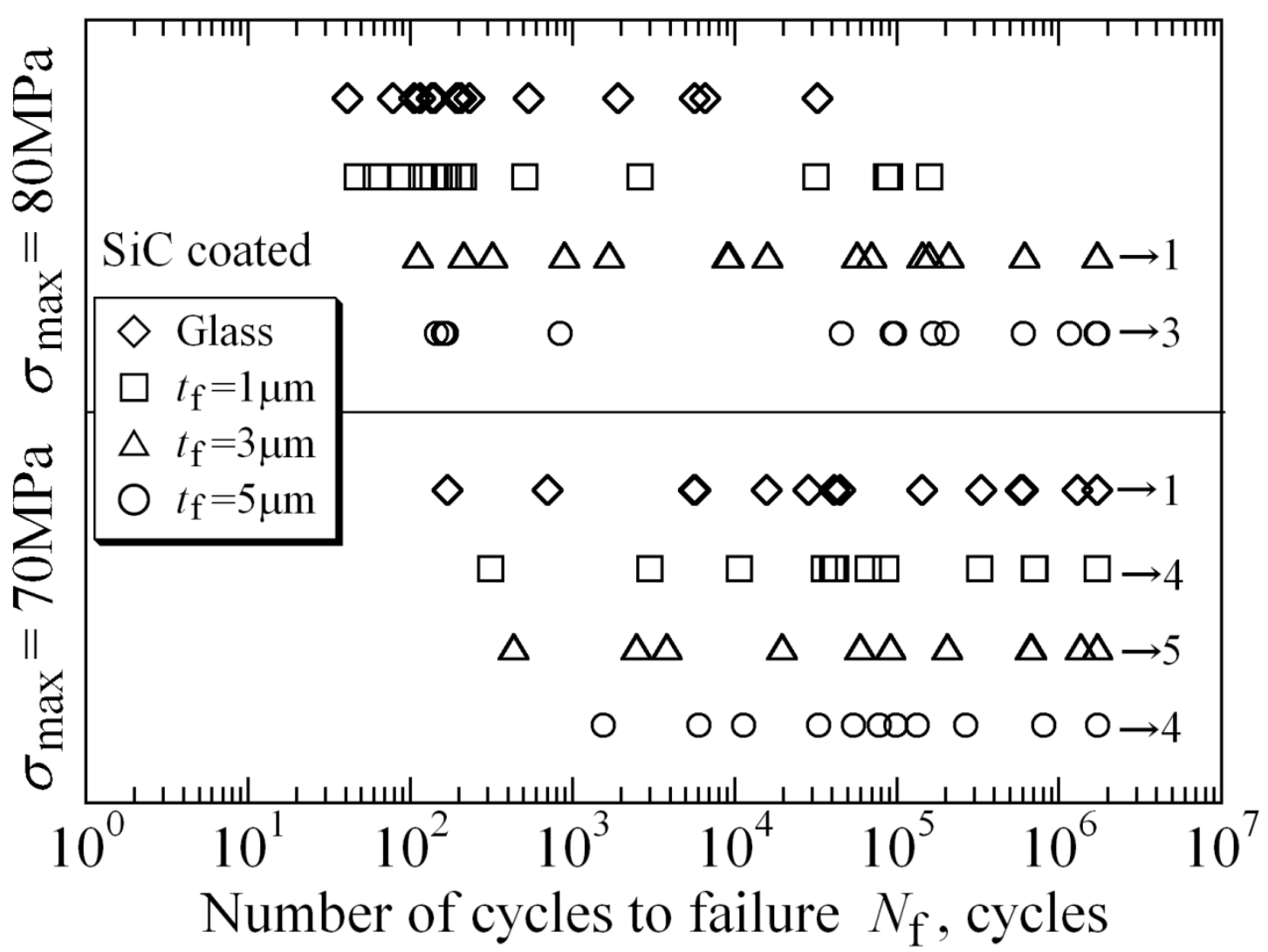

Fig. 2 Fatigue life of SiC coated glass under $\sigma_{\max }=70 \mathrm{MPa}$ and $80 \mathrm{MPa}$ 


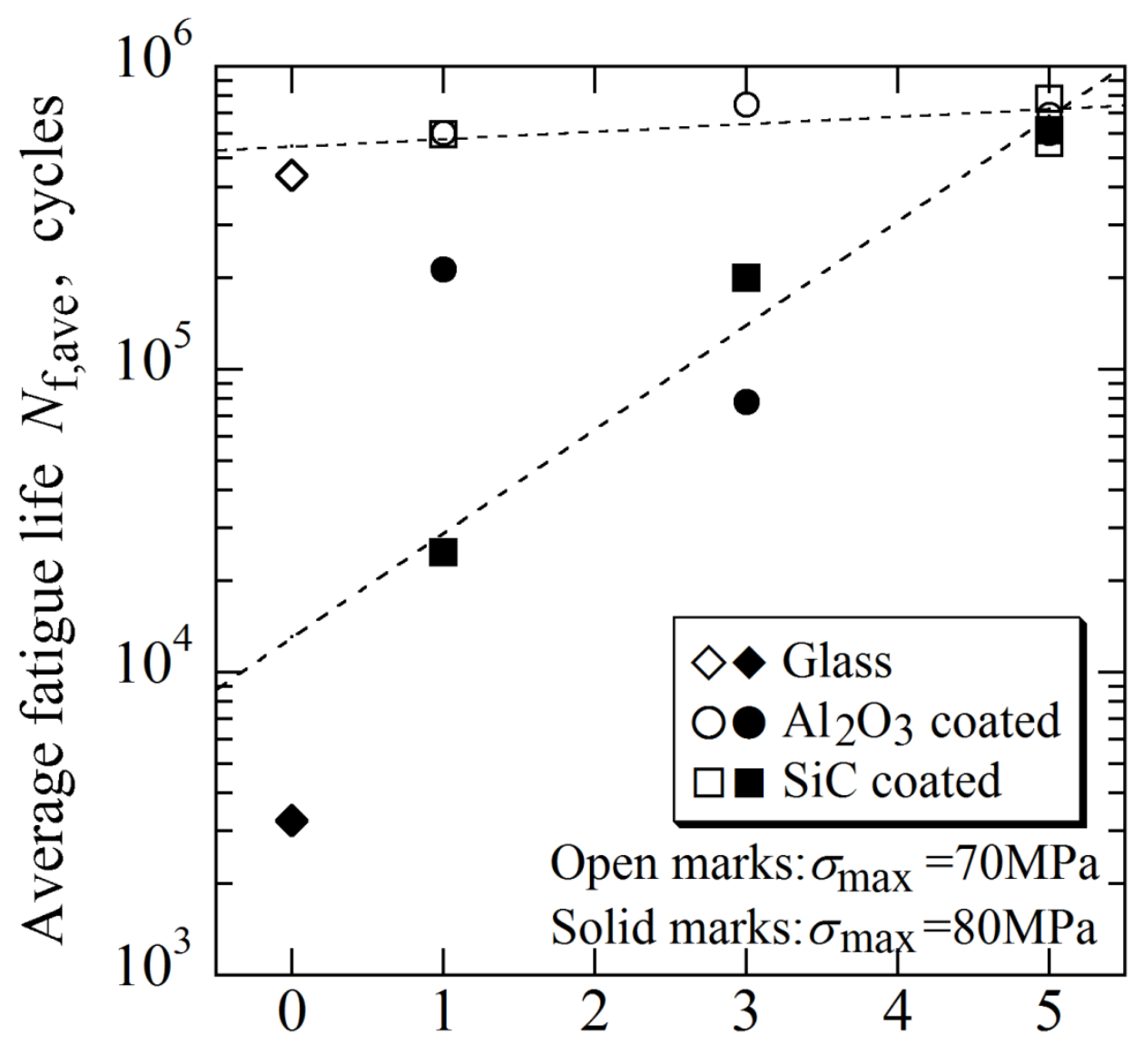

Film thickness $t_{\mathrm{f}}, \mu \mathrm{m}$

Fig. 3 Average fatigue life correlated with film thickness 


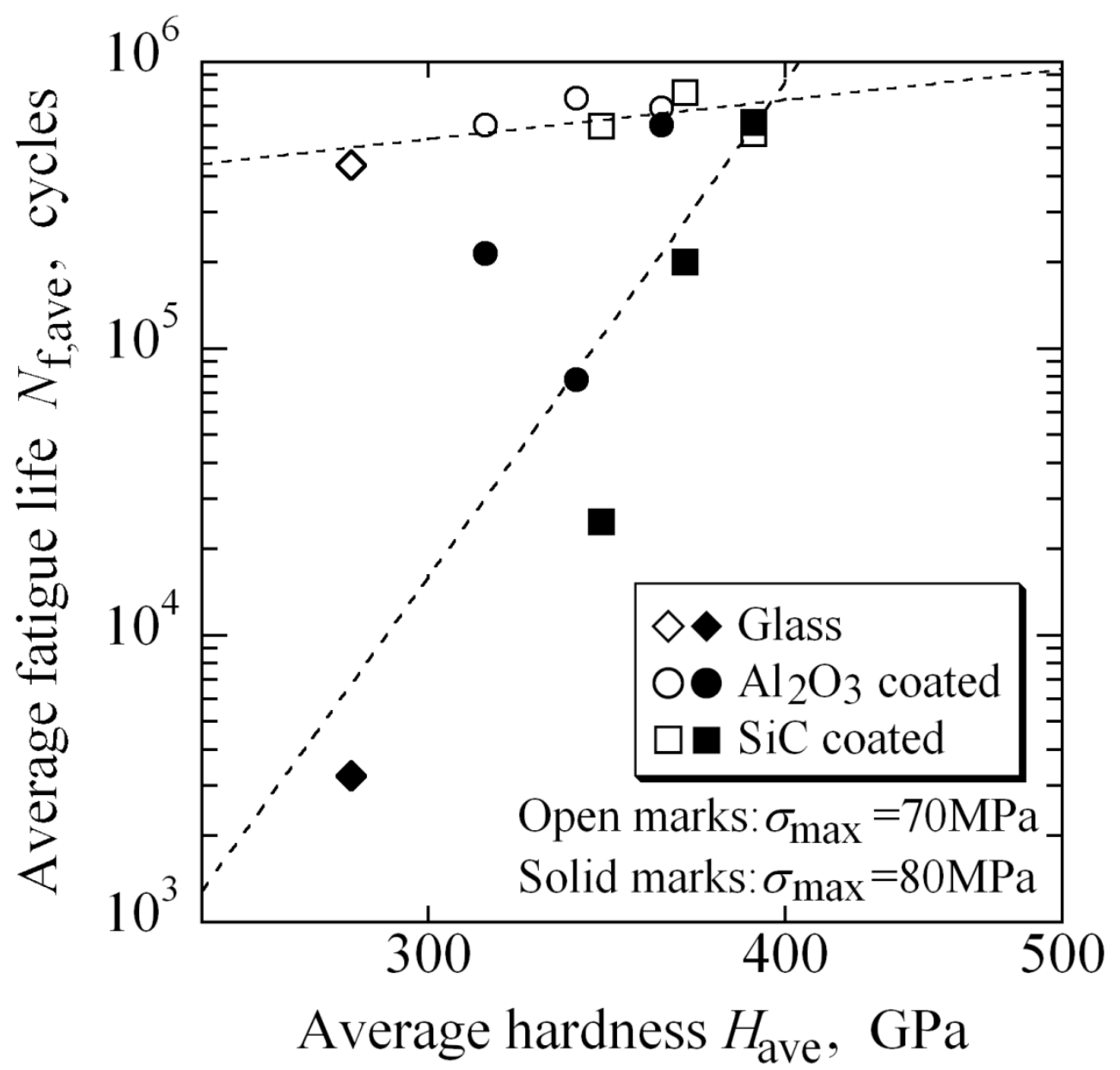

Fig. 4 Average fatigue life correlated with average hardness 


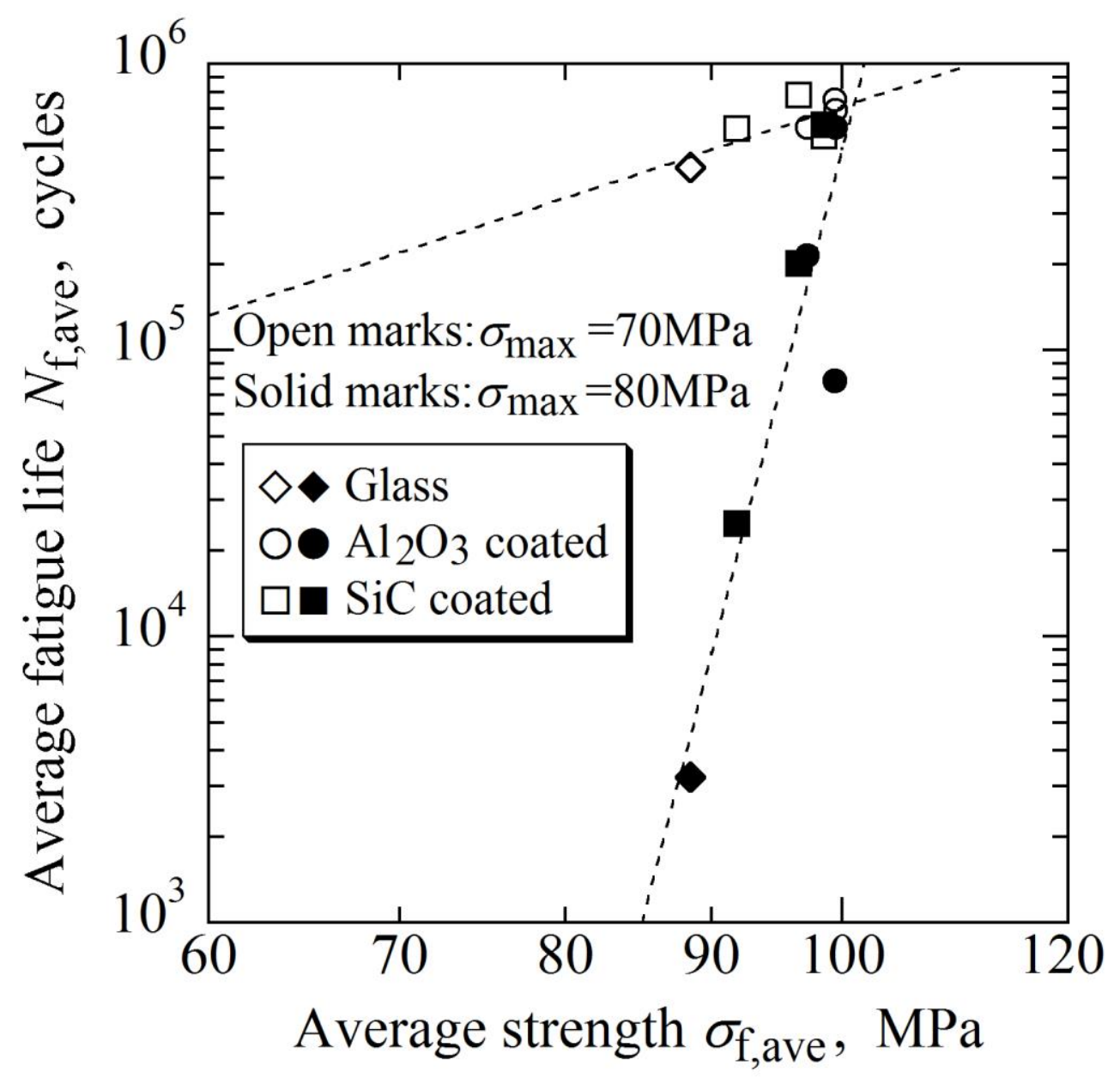

Fig. 5 Average fatigue life correlated with average strength 


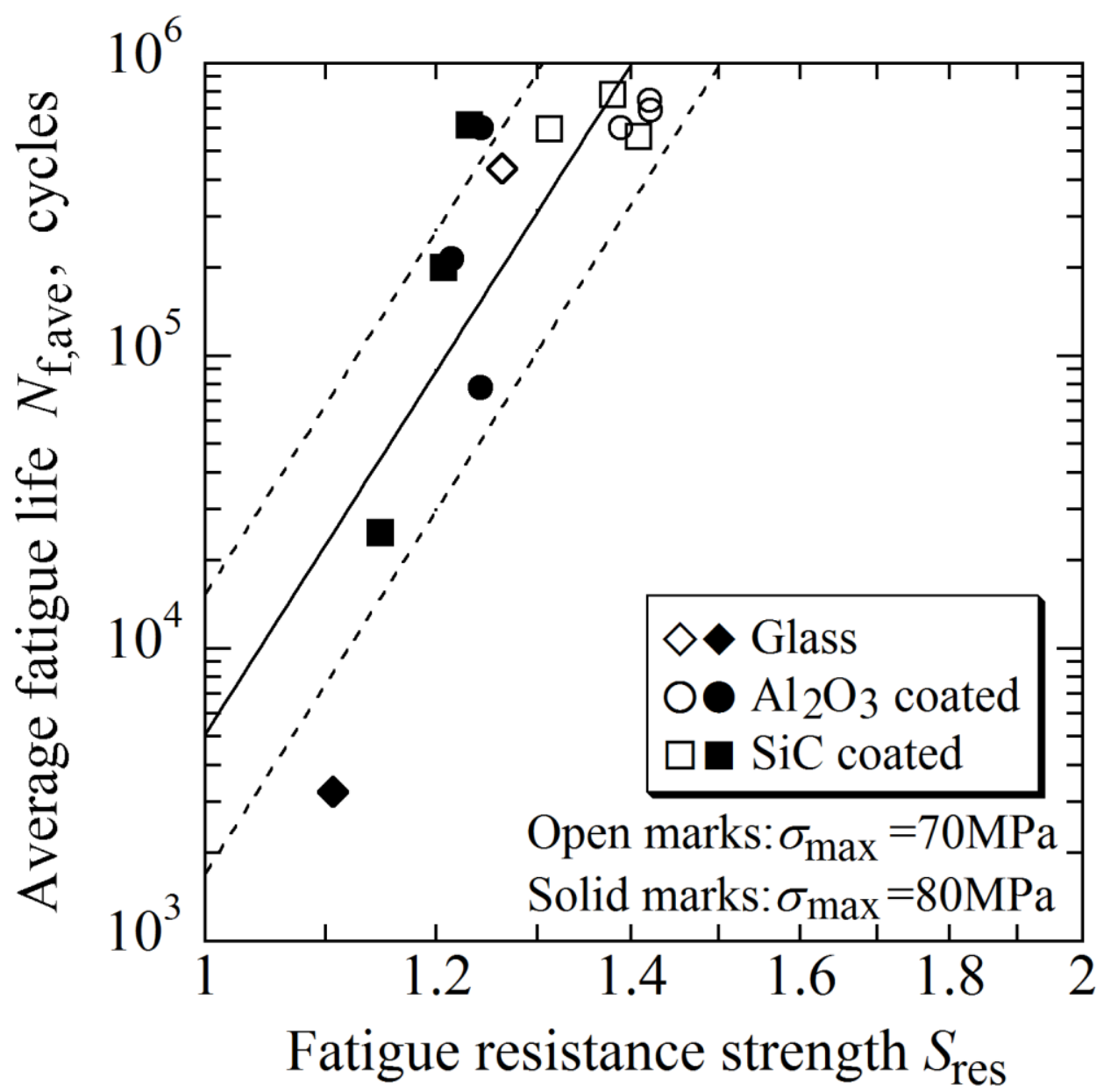

Fig. 6 Average fatigue life correlated with fatigue resistance strength 


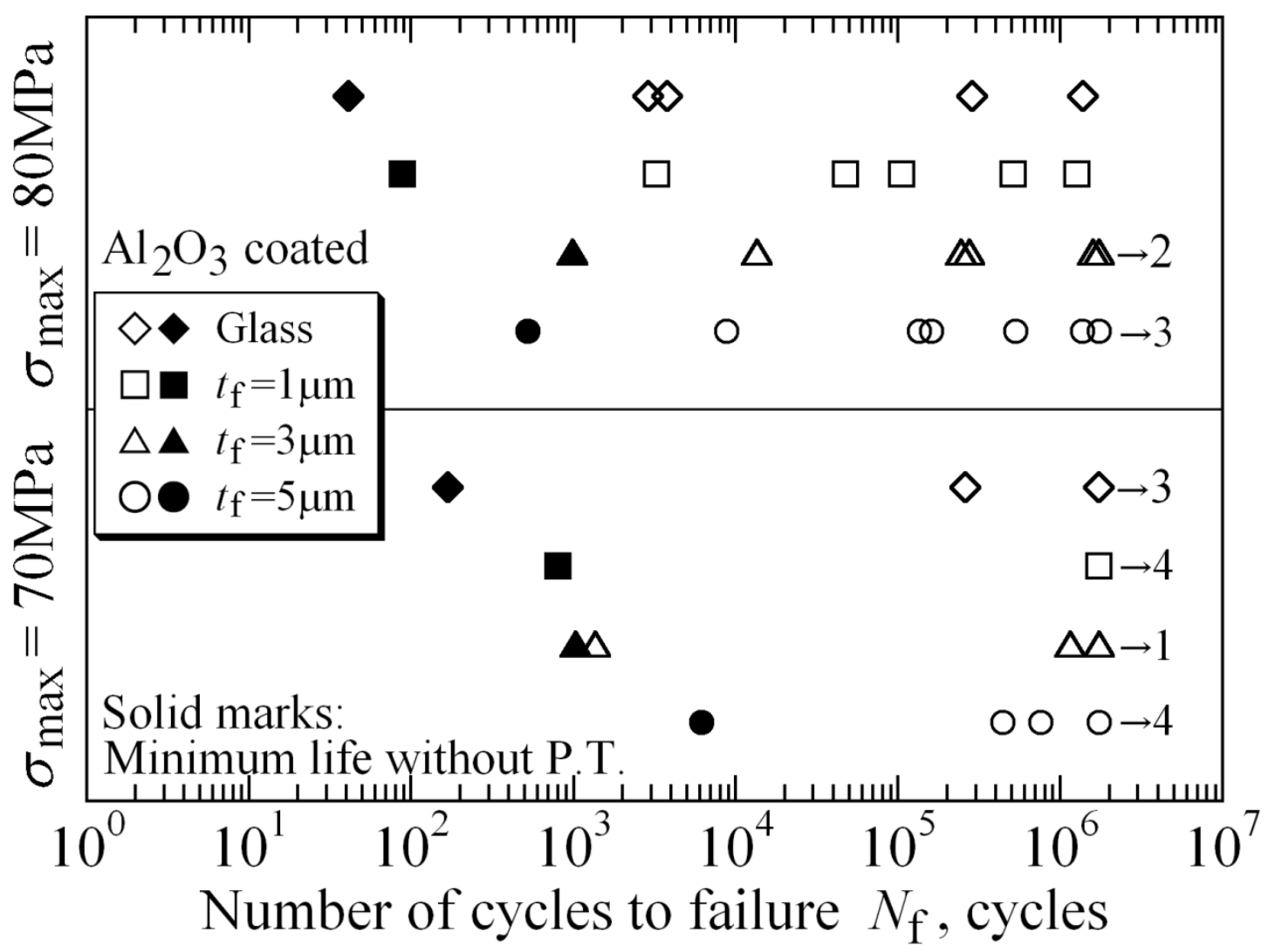

Fig. 7 Fatigue life of $\mathrm{Al}_{2} \mathrm{O}_{3}$ coated glass after proof testing

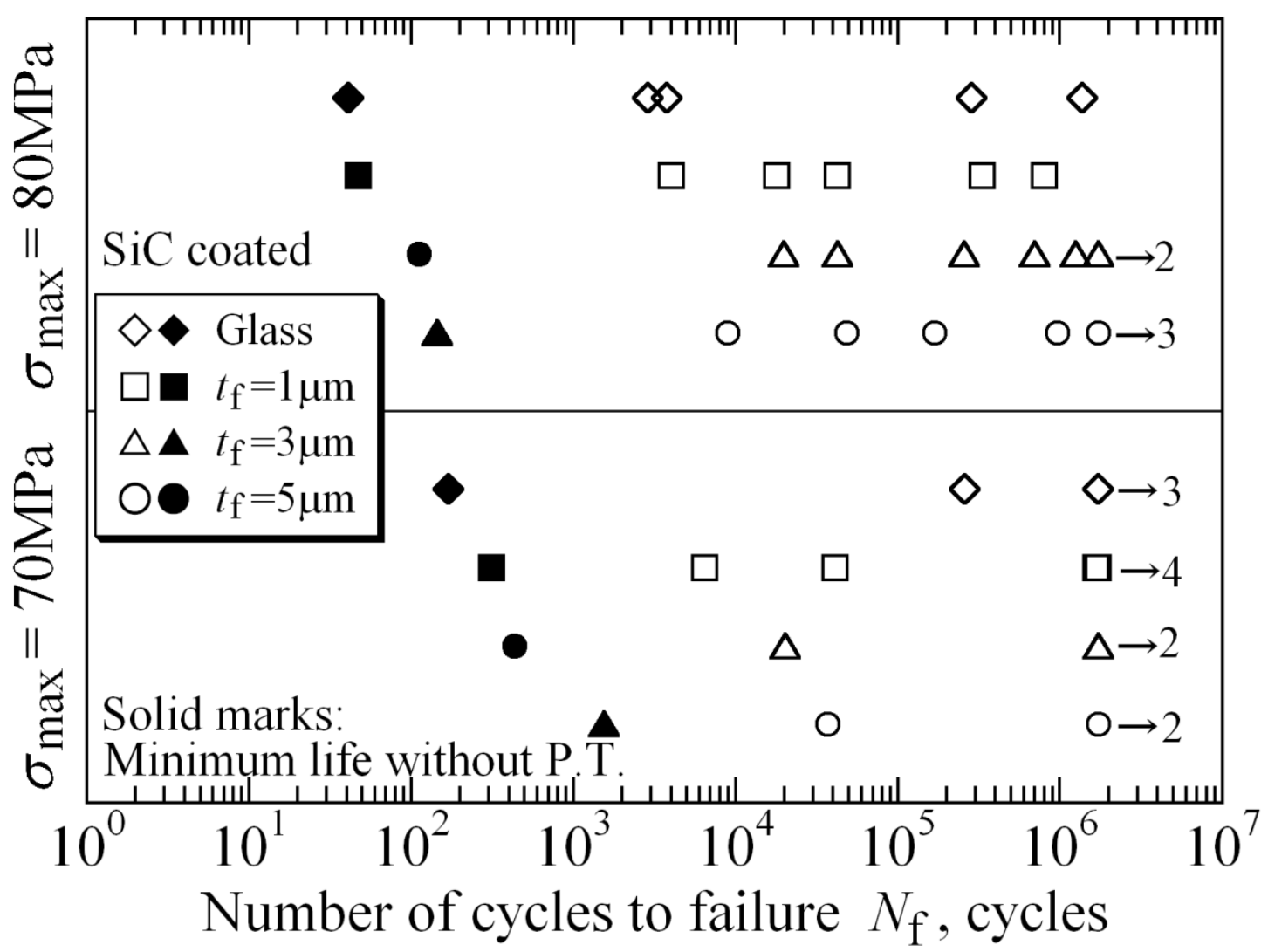

Fig. 8 Fatigue life of $\mathrm{SiC}$ coated glass after proof testing 


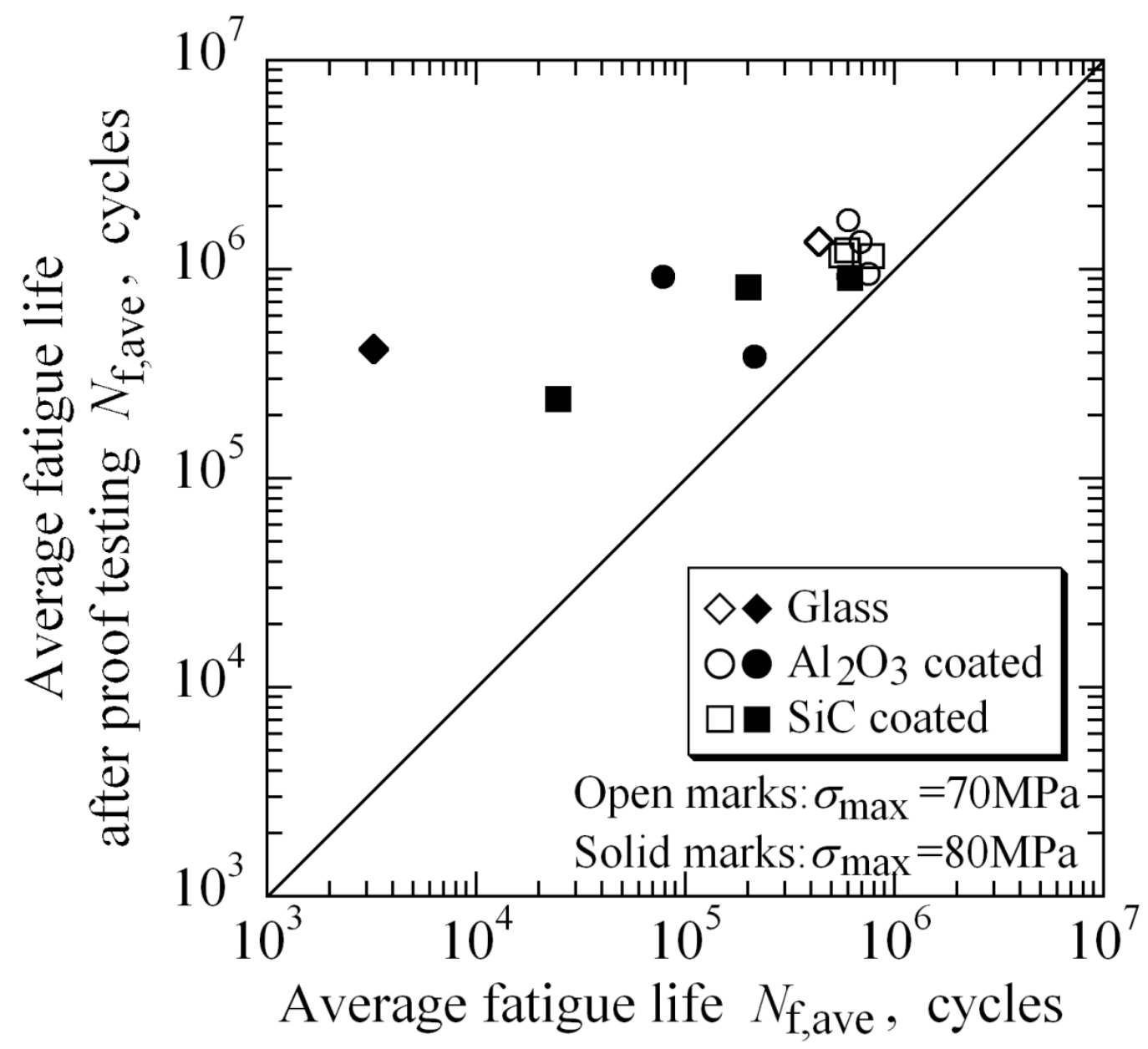

Fig. 9 Comparison of average fatigue lives after proof testing 


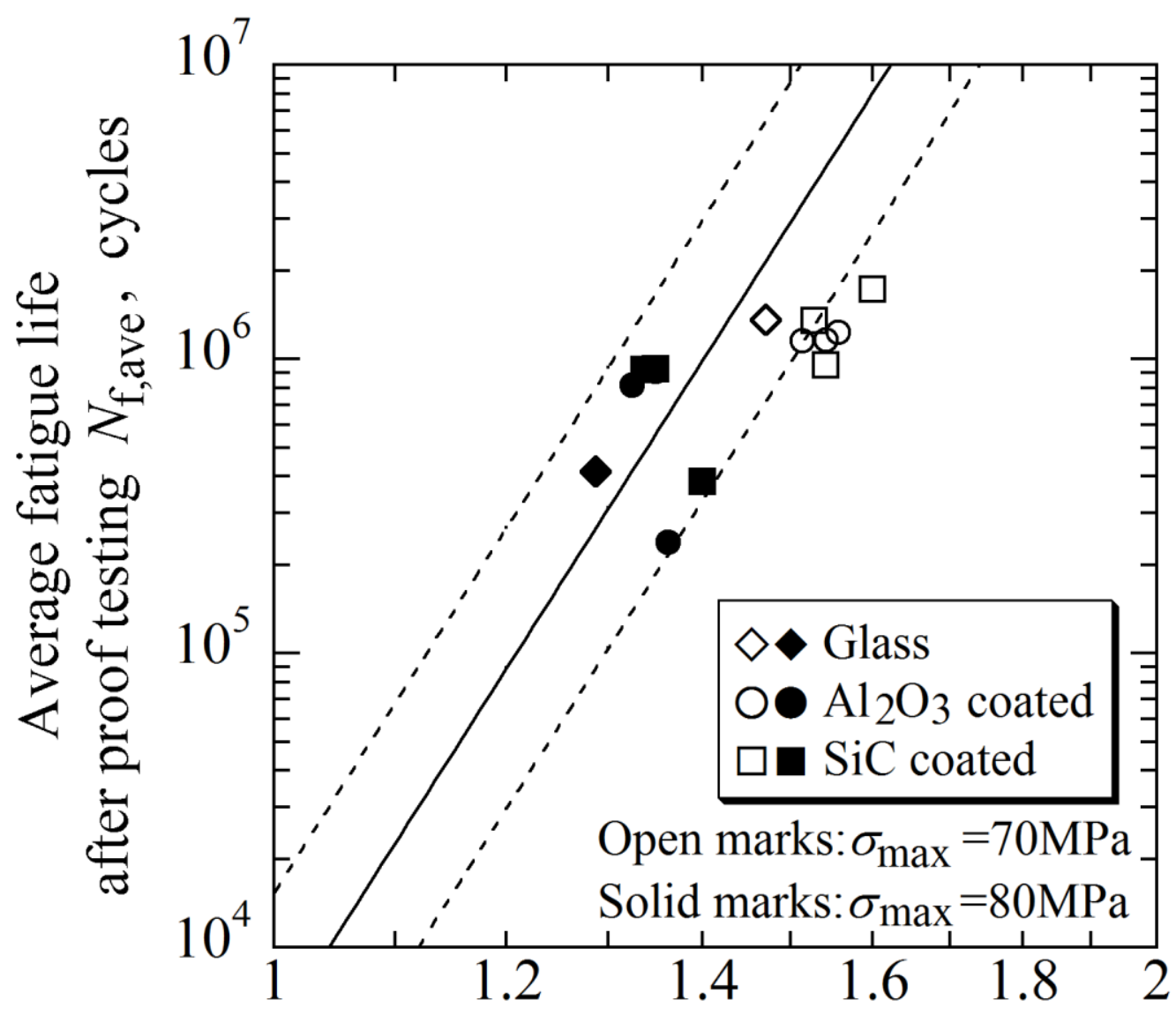

Modified fatigue resistance strength $S_{\text {res }}^{\prime}$

Fig. 10 Average fatigue life after proof testing correlated with modified fatigue resistance strength 